\title{
DIREITO CIVIL CONSTITUCIONAL E A FUNÇÃO SOCIAL DA POSSE: Reflexões Sobre o Acórdão ARE n. 1047694-RJ do Supremo Tribunal Federal
}

http://dx.doi.org/10.21527/2176-6622.2019.52.157-168

Recebido em: 4/9/2018

Modificações requeridas em: 1이일 2019

Aceito em: 15/10/2019

Marcelo de Mello Vieira

Mestrado em Direito pela Universidade Federal de Minas Gerais. Doutorando em Direito pela Pontifícia Universidade Católica de Minas Gerais - PUC-Minas. Professor de Direito Civil do Centro Universitário Unihorizontes. http://lattes.cnpq.br/7169118774782075. marcelomvieira@yahoo.com.br

\section{Marina Carneiro Matos Sillmann}

Mestrado em Direito Privado pela PUC-Minas. Graduação em Direito pela Universidade Federal de Uberlândia. Professora da Faculdade de Direito e Ciências Sociais do Leste de Minas (Fadileste). http://lattes.cnpq.br/6889554292137254. marinasillmann@hotmail.com

\section{RESUMO}

O presente artigo objetiva estudar a necessária reformulação do instituto da posse no contexto pós-CRFB/1988, focando na constitucionalização do Direito Civil brasileiro e nas modificações do direito de propriedade e seus impactos na posse, trazendo uma proposta de função social da posse. Foi utilizada a pesquisa jurídico-teórica valendo-se do raciocínio dedutivo. O trabalho utiliza como método de pesquisa a revisão bibliográfica e a análise do acórdão ARE n. 1047694, que trata a temática proposta. Concluiu-se que a constitucionalização do Direito Civil forçou uma releitura do conceito tradicional de posse, exigindo a presença da função social. Essa nova concepção contrasta com aquela adotada pelo STF no ARE n. 1047694, devendo ser feita uma análise específica para cada caso concreto antes de se determinar uma reintegração de posse.

Palavras-chave: Direito civil constitucional. Função social. Posse.

CONSTITUTIONAL CIVIL LAW AND THE SOCIAL FUNCTION OF POSSESSION: REFLECTIONS ON THE JUDGMENT IN ARE N. 1047694-RJ OF THE FEDERAL SUPREME COURT

\section{ABSTRACT}

This article aims to study the necessary reformulation of the institute of the possession in the post-CRFB / 1988 context, focusing on the constitutionalization of Brazilian Civil Law and the modifications of property rights and their impacts on tenure, bringing a proposal of social function of possession. It was used the legal-theoretical research using the deductive reasoning. The work uses as a research method the literature review and the analysis of the judgment ARE. 1047694 which deals with the proposed theme. It was concluded that the constitutionalization of Civil Law forced a rereading of the traditional concept of possession, requiring the presence of the social function. This new conception contrasts with that adopted by the STF in ARE $n$. 1047694, and a specific analysis should be made for each specific case before a repossession is determined.

Keywords: Constitutional civil law. Social function. Possession.

\section{SUMÁRIO}

1 Introdução. 2 A Constitucionalização do Direito Civil Brasileiro. 3 A Posse no Direito Civil Contemporâneo Brasileiro. 3.1 A Posse e a Propriedade: Conceito e Função Social. 3.2 Função Social da Posse. 4 Interpretação da Posse pelo Supremo Tribunal Federal: Análise do Acórdão ARE n. 1047694. 5 Conclusão. 6 Referências. 


\section{Direito自

\section{INTRODUÇÃO}

A Constituição da República Federativa do Brasil de 1988 (CRFB) (BRASIL, 1988) é um importante marco para a sociedade brasileira, pois inaugura no país um Estado Democrático de Direito. Fundada na dignidade da pessoa humana e nos valores sociais do trabalho e da livre-iniciativa, além de outros pilares (artigo 10 da CRFB/1988), essa nova ordem jurídica previu expressamente seus objetivos, estando entre eles a construção de uma sociedade justa e igualitária (artigo $3^{\circ}$, I da CRFB/1988), o que perpassa, também, pela efetivação dos direitos e garantias fundamentais.

No Direito Privado, essa mudança legal foi especialmente impactante, tanto pelo tratamento dado pelo texto constitucional a temas tradicionalmente trabalhados pelo Direito Civil quanto pelos influxos trazidos pelos fundamentos e objetivos da república e pelos direitos fundamentais, que exigiram que essa área do Direito fosse repensada.

A partir daí, fala-se em uma constitucionalização do Direito Civil, que significa retrabalhar os institutos próprios do Direito Privado de modo que estes se prestem a efetivar o programa constitucional nessa esfera. Esse fenômeno, que flexibilizou a rígida separação entre o Direito Público e o Direito Privado, trouxe um forte impacto em institutos tradicionais do Direito Civil, como a família, a empresa, o contrato e a propriedade, ao relacioná-los com os fundamentos e objetivos da República presentes no texto constitucional.

A posse é um desses clássicos institutos que tiveram de ser reformulados a partir dos ditames constitucionais. Tradicionalmente definida por meio dos conceitos elaborados pelos juristas alemães Friedrich von Savigny e Rudolf von Jhering, a posse também deve ser compreendida como um meio para concretizar esse programa constitucional traçado pela CRFB/1988, anteriormente mencionado. Com isso, o exercício dos direitos do possuidor está condicionado à destinação do bem de forma útil para a sociedade. Em outras palavras, para que a posse atenda sua função social, passou-se a exigir do possuidor a promoção de interesses existenciais para o correto exercício da posse.

O presente trabalho tem como objetivo tratar da necessária reformulação do instituto "posse" pós-CRFB/1988. Para tanto, inicialmente, traçar-se-á um panorama do Direito Civil brasileiro constitucionalizado. Posteriormente, abordar-se-á a posse nesse novo Direito Civil, destacando as modificações no direito de propriedade e seus impactos na posse, para, depois, trabalhar a função social da posse. Por fim, analisar-se-á o acórdão ARE n. 1047694, a fim de apurar como o Supremo Tribunal Federal está analisando a concepção de função social da posse.

Para este estudo foi utilizada a pesquisa jurídico-teórica, valendo-se do raciocínio dedutivo. O trabalho utiliza como método de pesquisa a revisão bibliográfica e a análise jurisprudencial do acórdão ARE n. 1047694 do Supremo Tribunal Federal sobre a temática proposta.

Justifica-se a relevância deste estudo em razão da necessidade de se compreender a reformulação dos conceitos clássicos do Direito Privado quando analisados sob o prisma da Constituição da República Federativa do Brasil de 1988, em especial, da influência da função social na posse.

\section{A CONSTITUCIONALIZAÇÃO DO DIREITO CIVIL BRASILEIRO}

O primeiro Código Civil Brasileiro (CCB) (BRASIL, 1916), conhecido como Código Beviláqua, adotou a concepção de codificação inaugurada na França pós-período revolucionário. Tal concepção representava o baluarte da mais moderna ciência jurídica da época e fundava-se na ideia de rígida separação entre os temas de Direito Público e de Direito Privado e na pretensão de esgotar em seu texto a abordagem de todo o Direito Civil. Baseado no individualismo e no voluntarismo (TEPEDINO, 2004), o CCB (BRASIL, 1916) consistia em um "produto de sua época e das forças sociais imperantes no meio em que surgiu. Feito por homens identificados com a ideologia dominante, traduz o sistema normativo de um regime capitalista colonial" (AMARAL, 1998, p. 117).

O Direito Civil brasileiro de então era marcado pela forte proteção ao patrimônio e também pelo individualismo jurídico, traços do pensamento jurídico liberal do final do século 18 e início do 19, regulando, especialmente, a atuação dos contratantes e do proprietário. Para Tepedino (2004, p. 2), tais sujeitos "[...] a nada aspiravam senão ao aniquilamento de todos os privilégios feudais: poder contratar, fazer circular as riquezas, adquirir bens como expansão da própria inteligência e personalidade, sem restrições ou entraves legais". 
Quando de sua promulgação, contudo, a sociedade brasileira apresentava uma concepção diferente do modelo liberal no qual o CCB (BRASIL, 1916) foi concebido, especialmente em razão da intensificação dos movimentos sociais e da crise do liberalismo na década de 30 do século 20 . A sonhada completude não se concretizou, uma vez que ficou clara a necessidade de promulgações das mais diversas leis esparsas, o que, de fato, ocorreu. Observou-se, ainda, naquele período, uma maior interferência do Estado na esfera privada, especialmente em razão da massificação das relações obrigacionais e dos contratos de adesão, exigência de um mercado que demandava celeridade. Com o intuito de buscar a igualdade material, surgiu o dirigismo contratual, que limitou a autonomia da vontade em prol dos interesses sociais, como a observância da boa-fé e da função social.

Em 1988, no entanto, a promulgação da CRFB/1988 inaugurou uma nova ordem jurídica, rompendo com o autoritarismo do período militar brasileiro, trazendo a dignidade da pessoa humana como um dos fundamentos do Estado Democrático de Direito Brasileiro (artigo 1ㅇIII) e a construção de uma sociedade livre, justa e igualitária como um de seus objetivos (artigo 3 이). Ela também assumiu um compromisso com a concretização de direitos e garantias fundamentais (artigos 50 a 17).

A nova ordem jurídica trouxe um impacto direto no modo de se trabalhar o Direito Privado, uma vez que seus institutos clássicos, como o contrato e a propriedade, deveriam, agora, atender aos fundamentos e objetivos do Estado Democrático de Direito. No Direito Privado, a dignidade da pessoa humana representou a obrigação de reinterpretarem-se os institutos de modo que o foco se tornasse a pessoa humana e a efetivação dos direitos fundamentais. Essa mesma interpretação também deveria ser voltada para a promoção de uma sociedade justa, livre e igualitária, o que se concretiza quando os seus institutos cumprem a proposta de função social.

A CRFB/1988 foi responsável ainda por incorporar no texto constitucional normas de conteúdo típico de Direito Privado, impactando na estrutura do Direito Civil e no seu modo de se relacionar com o Direito Público (MORAES, 1991). Com isso, atenuou-se a rígida separação entre Direito Público e Direito Privado, exigindo que o Direito fosse trabalhado como um ordenamento jurídico unitário e hierarquicamente organizado, no qual os princípios constitucionais irradiam-se para todos os seus ramos (MORAES, 1991).

Assim, fala-se em uma constitucionalização do Direito Civil, devendo isso ser entendido como a leitura da legislação civil sob o crivo dos princípios constitucionais, com o intuito de efetivar o programa constitucional na esfera privada (FIUZA, 2007). Trata-se, portanto, de um Direito Civil no qual se sente a influência dos princípios constitucionais, especialmente em espaços que eram tradicionalmente dominados pela liberdade individual (TEPEDINO, 2007), e que está comprometido na construção de um direito "que também seja 'livre, justo e solidário'” (SCHREIBER; KONDER, 2006, p. 10). Em razão disso, deve-se afirmar que os direitos constitucionais passaram a permear os direitos presentes na codificação civilista em uma relação de complementariedade.

Para Tepedino (2003), a absorção desses valores não patrimoniais, bem como a funcionalização dos institutos de Direito Civil, levou a três relevantes conquistas para o Direito brasileiro: a primeira delas consistiu na compreensão de que os conceitos jurídicos não são neutros, nem absolutos; a segunda foi a já mencionada superação da dicotomia entre Direito Público e Privado; e a terceira, por fim, foi o entendimento de que temas de Direito Privado não são unicamente tratados pelo Código Civil, mas também pelo texto constitucional. Ainda conforme Tepedino (2003), tais constatações, especialmente a primeira, permitiram a superação da visão tradicional de um Direito Privado permeado por categorias absolutas e acríticas para a compreensão de um direito como um fenômeno social e histórico e que deve ser periodicamente revisto.

Cumpre ressaltar que, apesar de todas as modificações do Direito Civil constitucional, o CCB (BRASIL, 2002) mostrou-se conservador, ainda que tivesse apresentado uma evolução em alguns aspectos. O modelo de texto legislativo do CCB (BRASIO, 2002) utilizou cláusulas gerais e conceitos jurídicos indeterminados, substituindo a rigidez do modelo anterior (BRASIL, 1916). A inserção das cláusulas gerais, contudo, foi insuficiente e exigiu que o intérprete fosse capaz de estabelecer o completo diálogo do Direito Civil com os princípios constitucionais, uma vez que a Constituição é o centro do ordenamento jurídico. 
Um dos institutos tradicionais do Direito Privado, que foi significativamente alterado pelo Direito Civil constitucional, foi a posse. Considerada como um dos Diretos das Coisas, a posse foi analisada de modo compatível com a ampla proteção que se conferia ao proprietário. Após 1988, teve incorporada em seu conceito a noção de função social.

\section{A POSSE NO DIREITO CIVIL CONTEMPORÂNEO BRASILEIRO}

A posse no Direito nacional sempre foi rodeada por dúvidas e polêmicas. Castro (2010) já advertia que uma das tarefas mais árduas do Direito é a de traçar o conceito e o conteúdo da posse. Diversos juristas nacionais e estrangeiros abraçaram essa missão, mas ainda não há um consenso sobre a temática. Inegavelmente, foram os juristas alemães Friedrich von Savigny e Rudolf von Jhering que mais influenciaram os debates sobre a posse. Desse modo, qualquer discussão sobre o tema deve passar pela análise das teorias da posse de cada um desses autores.

Conforme aponta Fiuza (2014), ao trabalhar o instituto, Savigny tomou como ponto de partida a concepção de detenção, ou seja, a possibilidade física que um sujeito teria de dispor da coisa. Para diferenciar a posse da detenção, Savigny acrescentou a vontade de possuir a coisa como um dos elementos do instituto. Sua teoria recebeu o nome de teoria subjetiva e defendia que a posse seria composta por dois elementos: corpus e animus domini. O primeiro elemento, de natureza objetiva, compreenderia o poder físico exercido sobre a coisa, e o segundo, de natureza subjetiva, consistia em ter a coisa como sua (STANLEY, 2015).

Já na visão de Jhering, o corpus seria compreendido como a exteriorização do domínio, enquanto o animus, ou affectio tenendi, representava o agir do possuidor como se a coisa the pertencesse (STANLEY, 2015). Jhering criticava a teoria subjetiva pela ênfase que Savigny concedia ao elemento animus (FIUZA, 2014), mostrando que nem todo possuidor tem a vontade de ser dono. Com isso, o autor entendeu ser mais pertinente conferir destaque ao corpus; assim, sua teoria foi denominada de objetiva (DONIZETTI; QUINTELLA, 2014).

Cumpre destacar que, apesar de ambos autores trabalharem com os mesmos elementos para conceituar a posse, para Savigny havia posse apenas quando presentes os dois elementos, enquanto para Jhering bastava o corpus ou o animus para a caracterizar (STANLEY, 2015).

O CCB (BRASIL, 2002) adotou, em regra, ${ }^{1}$ a teoria objetiva de Jhering para caracterizar a posse, uma vez que a exigência presente no artigo 1.196 é apenas da conduta de proprietário, dispensando a apreensão física ou a vontade de ser dono. Somente esses clássicos elementos, todavia, foram ineficazes para trazer a posse ao paradigma do Direito Civil constitucional. Ela necessitou da inclusão de um novo elemento: a função social, que seria condição de legitimidade para o exercício do direito pelo possuidor (SILVA; SETTI, 2017).

\subsection{A posse e a propriedade: conceito e função social}

Apesar do consenso quanto aos elementos da posse, não há um conceito de posse legalmente definido, tendo a legislação apresentado apenas o conceito de possuidor como "todo aquele que tem de fato o exercício, pleno ou não, de algum dos poderes inerentes à propriedade" (artigo 1.196, BRASIL, 2002). Houve ainda a vinculação da noção de posse à propriedade, conforme depreende-se deste mesmo dispositivo. Em razão dessa conexão de posse com o conceito de propriedade, mostra-se pertinente compreender o tratamento jurídico conferido a este segundo instituto a fim de assimilar a posse no contexto do Direito Civil constitucional.

O Direito nacional também não traz um conceito legal de propriedade, mas é possível traçar o seu significado. Inspirada em ideais liberais, a propriedade era vista como o direito de o proprietário usá-la, dispô-la, gozá-la e reivindicá-la de forma exclusiva, devendo os não proprietários apenas se abster de praticar qualquer ato contrário aos interesses do proprietário. Percebe-se que havia uma valorização dos aspectos individualistas da propriedade, entendida com um direito subjetivo, havendo poucas restrições ao exercício dos direitos

\footnotetext{
Em que pese a adoção da teoria de Jhering pelo CCB (BRASIL, 2002), o Direito nacional adota a teoria de Savigny quando trata da usucapião no artigo 1.238 do CCB (BRASIL, 2002), pois exige-se que o sujeito possua a coisa como dono. A usucapião, por se tratar de uma forma de aquisição da propriedade a partir da manutenção da posse do bem por um determinado período de tempo, se adequa melhor à proposta de Savigny, uma vez que um de seus requisitos inerentes é o animus (ter a coisa como se fosse sua).
} 
do proprietário. Cuida-se de uma visão da propriedade oriunda dos processos da Revolução Francesa, conferindo ao proprietário plenos e absolutos poderes, sendo o direito de propriedade algo absoluto, inviolável e sagrado (MOTA PINTO et al., 2012).

Essa noção individualista da propriedade começou a ser atenuada com previsões legais, como a da Constituição da República de 1934, que estabelecia em seu artigo 113 "17" que o direito de propriedade não poderia ser exercido contra o interesse social ou coletivo. Os textos constitucionais posteriores repetiram tal disposição, mas pouco se alterou no tratamento jurídico do instituto. Foi a CRFB/1988 a responsável por eliminar o perfil exclusivista da propriedade, dando-lhe nova roupagem ao elevar a função social a princípio constitucional (STANLEY, 2015).

A função social é função e princípio. Função é a finalidade de um instituto, de um modelo jurídico, no caso a propriedade. Todo modelo jurídico compõe-se de estrutura e função. A gênese e a forma estão na estrutura; a finalidade, o papel a ser cumprido na função. Por função social da propriedade entenda-se a função que o dono deve atribuir às suas coisas, ao exercer seus direitos sobre elas, basicamente, ao usar, fruir e dispor. Essa função deve ser, na medida do possível e quando for o caso, útil à coletividade [...] (FIUZA, 2014, p. 947).

Como princípio, a função social representa a norma jurídica que cuida das soluções para que seja atendida a função social em caso de descumprimento pelo proprietário, e que também limita o exercício absoluto do direito de propriedade (FIUZA, 2014). A função social da propriedade tem previsão constitucional, tendo a CRFB/1988 a abordado de duas maneiras distintas: a primeira como direito fundamental individual vinculado a uma função social (artigo 5o caput, XXII e XXIII) e a segunda como um princípio da ordem econômica (artigo 170, III). A vinculação do direito de propriedade ao exercício da função social significa que a proteção aos direitos do proprietário de perpetuidade e exclusividade são garantidos apenas quando a propriedade cumprir sua função social (FARIAS; ROSENVALD, 2014). Ademais, tem-se que, em virtude da funcionalização do instituto, há um dever de este propiciar o pleno desenvolvimento da pessoa humana (TEPEDINO, 2007). Cumpre ressaltar ainda que a funcionalização da propriedade deve ser interpretada em conjunto com os princípios constitucionais da dignidade da pessoa humana (artigo $1^{\circ}$, III), da solidariedade (artigo $3^{\circ}$ ), da erradicação da pobreza e redução das desigualdades sociais (artigo $3^{\circ}$, III e IV) e com necessidade de promoção dos direitos fundamentais individuais e sociais (artigo 50 a 11).

Assim, a função social da propriedade não é uma limitação ao direito de usar, gozar, dispor e reivindicar do proprietário, mas, sim, parte do próprio conceito do direito, ou seja, ele conforma a sua característica noção atual de propriedade (CASTRO, 2010, p. 64-65). Ela impõe ao proprietário deveres de agir para garantir e promover os valores que fundamentam o ordenamento jurídico (PERLINGIERI, 2002, p. 226). Pode-se afirmar, então, que a

[...] função social penetra na própria estrutura e substância do direito subjetivo, traduzindo-se em uma necessidade de atuação promocional por parte do proprietário, pautada no estímulo à obrigação de fazer, consistentes em implementação de medidas hábeis a impulsionar a exploração racional do bem, com a finalidade de satisfazer os seus anseios econômicos sem aviltar as demandas coletivas, promovendo o desenvolvimento econômico e social, de modo a alcançar o valor supremo no ordenamento jurídico: a Justiça (FARIAS; ROSENVALD, 2014, p. 272).

Supera-se, assim, a visão tradicional na qual o proprietário podia exercer seus direitos com grande liberdade e os não proprietários apenas possuíam o dever de não influir na propriedade. Na propriedade funcionalizada, o proprietário e os não proprietários possuem direitos, deveres, ônus e faculdades recíprocas, não havendo mais uma relação de subordinação, mas de cooperação, podendo, em alguns momentos, prevalecer o interesse do proprietário e, em outros, o interesse de terceiros (PERLINGIERI, 2002).

O próprio texto constitucional encarregou-se de distinguir e dar concretude à função social da propriedade urbana e da propriedade rural. Em relação à propriedade urbana, ela será atendida quando a propriedade deferir ao disposto no plano diretor da cidade (artigo $182 \S 2^{\circ}$, CRFB) (BRASIL, 1988). Caso o proprietário não atenta a tais determinações, o município poderá empregar sanções para que passe a utilizar de forma adequada seu bem, que vão, progressivamente, do parcelamento e edificação compulsórios, passando pelo estabelecimento do imposto predial e territorial urbano até a desapropriação (artigo $182 \S 4^{\circ}$; Lei no 10.257/2001) (BRASIL, 2001b). 


\section{Direito自

Em relação à propriedade rural, o artigo 186 da CRFB (BRASIL, 1988) dispõe que sua função social é cumprida quando se efetivam concomitantemente o aproveitamento racional e adequado, a utilização adequada dos recursos naturais disponíveis, a preservação do meio ambiente, a observância das disposições que regulam as relações de trabalho e a exploração que favoreça o bem-estar dos proprietários e dos trabalhadores (artigo 182 §4ㅇ). O não cumprimento da função social rural é sancionado com a desapropriação (artigo 184).

Da mesma forma que essa funcionalização impõe direitos e deveres aos proprietários, também os particulares são sujeitos ativos e passivos de direitos, deveres, faculdades, ônus e sujeições (VIEIRA, 2015). A propriedade deixa de ser encarada como um direito subjetivo e passa a ser vista como uma situação subjetiva complexa (FARIAS; ROSENVALD, 2014). ${ }^{2}$

César Fiuza (2014) destaca que, nas relações jurídicas reais, aquelas que, conforme as teorias personalistas, existem entre o titular do bem (sujeito ativo) e os não titulares do bem (sujeito passivo) também são regidas pelo princípio da solidariedade. Para ele, "as relações reais, assim como as obrigacionais, são relações em cooperação, em que as partes podem não só exigir, mas também esperar uma atitude solidária uma da outra. Isso significa que titulares e não titulares devem agir solidariamente." (FIUZA, 2014, p. 935). Este princípio não legitima a violência contra a propriedade, mas, sim, traz um dever de cooperação, sem abusos, entre o titular e o não titular do direito de propriedade.

A função social da propriedade, portanto, modificou a maneira como o proprietário pode usar, gozar, dispor e reivindicar, e, sendo o possuidor aquele que tem de fato o exercício de algum desses poderes, pode-se afirmar que a posse também teve sua natureza modificada.

\subsection{Função social da posse}

Nenhum dos textos constitucionais brasileiros fizeram menção à função social da posse. Apesar de não ter sido expressa no texto constitucional nem na legislação civilista, entretanto, esta é uma decorrência lógica da necessidade de releitura do fundamento e do conteúdo da posse em razão da aplicação dos princípios constitucionais ao instituto e do seu papel dentro do Direito Civil constitucionalizado (ROSA, 2007). No mesmo sentido,

Quanto à função social da posse, embora não se encontre expressamente regulamentada, é possível, quando nada, deduzi-la da própria função social da propriedade, uma vez que a posse consiste exatamente no exercício dos direitos de dono. Evidentemente, que, diante do sistema impresso pelo ordenamento constitucional, a função social pode ser também derivada da importância da posse como instrumento de promoção da dignidade humana (FIUZA; SANTOS, 2015, p. 283).

Para Fiuza (2014), em diversos casos a posse vem desacompanhada da propriedade e, ainda assim, independentemente da previsão legal expressa, há que se falar em função social da posse como instrumento de promoção da dignidade humana. O mesmo autor (2014, p. 1.090) ressalta ainda que a

[...] posse ganha autonomia em relação à propriedade, como instrumento de promoção da vida digna. Mais uma vez aqui, pensemos na situação de milhares de pessoas que não têm casa própria, são locatários, possuidores de imóvel residencial alheio. Sua posse deve ser protegida, ainda que contra o próprio dono [...]. ${ }^{3}$

Com isso, afirmar que a posse possui uma função social significa que ela "[...] apresenta uma destinação extrínseca (social, econômica, ambiental, cultural, etc.) a ser obedecida pelo detentor daquele direito, não mais apenas a moral e o respeito aos direitos alheios (evitar danos)" (CASTRO, 2010, p. 74).

Assim como ocorreu com a propriedade, a função social passou a exigir do possuidor obrigações positivas para o correto exercício da posse, uma vez que o instituto também deve ter como objetivo a promoção de interesses existenciais. Rosa (2007) salienta que a função social da posse tem uma nítida ligação com as

\footnotetext{
2 Para Perlingieri: "a complexidade das situações subjetivas - pela qual em cada situação estão presentes momentos de poder e de dever, de modo que a distinção entre situações ativas e passivas não deve ser entendida em sentido absoluto - exprime a configuração solidarista do nosso ordenamento constitucional" (PERLINGIERI, 2008, p. 678).

Nos termos da Lei no 8.245/1991.
} 
necessidades sociais básicas do ser humano, como a moradia e o trabalho. Nesse contexto, pode-se concluir que "não há melhor demonstração de funcionalização da posse do que o efetivo cultivo das terras ou com princípio dele e morada habitual" (MIRANDA FILHO, 2010, p. 25, grifos no original). Assim, além da moradia, a posse também se tornou essencial para atender à outra necessidade humana fundamental: o trabalho. Para Vieira (2015, p. 20),

Logo, hoje não basta se falar em corpus ou animus (affectio tenendi). A configuração da posse exige uma função social, ou seja, que seu exercício busque efetivar direitos fundamentais. Assim, como ocorreu com o direito de propriedade, a função social passou a integrar a própria noção atual de posse, também não podendo ser vista com (sic) uma mera limitação. A posse que supostamente dava dinamicidade à propriedade, passa a ser ainda mais dinâmica com a função social.

Entende-se, portanto, como uma possível definição de posse, uma situação jurídica complexa por meio da qual se exerce um dos poderes ligados à propriedade, efetivando-se uma necessidade básica do cidadão ligada a um direito existencial, ou seja, uma função social. Essa concepção serviria como ponto de partida para a interpretação constitucional da posse, que não pode olvidar os elementos presentes no caso concreto (VIEIRA, 2015).

Cumpre ressaltar que, para essa interpretação se efetivar, a

[...] função social da posse, deverá ser construída interpretativamente, com criatividade, no sentido de implementar a máxima eficácia social, harmonizando o seu exercício com aqueles valores, não só pela usucapião, em suas modalidades previstas no Código Civil, mas, sobretudo, no caráter funcional que a posse tem, como meio jurídico e pacífico de acesso aos bens e de concretização do interesse social, que deve prevalecer e preponderar sobre o individual, mormente quando este revestir-se apenas de caráter patrimonial (MIRANDA FILHO, 2010, p. 55).

Em termos concretos, a função social da posse é expressamente reconhecida no Direito nacional quando se analisam as normas que tratam da usucapião, sendo justificativa para a redução em cinco anos, tanto para a usucapião ordinária quanto extraordinária (artigo 1.242, parágrafo único e 1.238, parágrafo único do CCB) (BRASIL, 2002). Ambos os dispositivos preveem que será adquirida a propriedade de um imóvel por aquele que possui justo título e boa-fé e está na posse do imóvel por 10 anos ou por 5 , se o imóvel tiver sido adquirido onerosamente (1.242), ou, ainda, por 15 anos se não possuir justo título ou boa-fé (1.238). O parágrafo único do artigo 1.238 aduz a redução do prazo para 10 anos, caso o sujeito tenha estabelecido naquele lugar sua moradia ou tenha realizado naquele imóvel obras ou serviços de caráter produtivo.

Em relação à proteção possessória, conforme aduz Áurea Castro (2010), o exercício da função social da posse do imóvel, tanto para trabalho quanto para moradia, consiste em requisito essencial para garanti-la. Nesse contexto, nota-se que essa função social da posse se tornou fundamento autônomo capaz de embasar o uso das ações possessórias.

Assim, a função social da posse teria seu conteúdo delimitado diante da análise da situação concreta. Conforme mencionado anteriormente, não se trata de uma limitação do exercício dos direitos do possuidor, e sim algo inerente ao próprio instituto da posse, relacionando-a à concretização dos direitos fundamentais, dos princípios e dos objetivos da República no projeto do Direito Civil constitucional.

\section{INTERPRETAÇÃO DA POSSE PELO SUPREMO TRIBUNAL FEDERAL: Análise do Acórdão ARE N. 1047694}

Embora tenha sido promulgado o CCB (BRASIL, 2002), o referido código manteve-se, em grande parte, fiel à codificação anterior, não sendo completamente adaptado aos ditames da CRFB/1988. Por esse motivo, dentro do Direito Civil atual, essa leitura constitucional dos institutos tem ficado a cargo dos juristas. Coube a eles, por meio da interpretação jurídica, elaborar parâmetros que auxiliem os julgadores a modular conceitos abertos e cláusulas gerais à luz dos princípios constitucionais em uma interpretação criativa.

A interpretação criativa é aquela que parte de um caso concreto para delimitar o significado dos conceitos jurídicos empregados, considerando suas peculiaridades. No caso da posse, significa abandonar o processo de interpretação exegético, baseado somente nas normas abstratas, e considerar a posse como instituto 
dinâmico e social, indo além de seu aspecto patrimonial (proteção à propriedade) e sendo vista pelo viés de proteção e promoção da pessoa (SOUZA, 2014). Com isso, tem-se os subsídios necessários para a construção argumentativa da melhor decisão possível para aquela situação fática.

Em relação à aplicação da proposta da constitucionalização do Direito Civil na prática jurídica, tem-se que o Supremo Tribunal Federal (STF) analisou, no ano de 2017, a questão da função social da posse nos casos de inadimplemento contratual de um imóvel do Programa de Arrendamento Residencial (PAR).

O PAR é um programa de iniciativa do Ministério das Cidades, sendo a Caixa Econômica Federal (CEF) o agente executor, e o Fundo de Arrendamento Residencial (FAR) o financiador. Ele intenta auxiliar municípios e Estados a atenderem à necessidade de moradia daquelas pessoas que vivem em centros urbanos com renda até $\mathrm{R} \$ 1.800,00$. As unidades disponibilizadas pelo PAR são arrendadas, havendo opção de compra do imóvel ao final do período contratado (CEF, 2017). Com isso, torna-se um dos responsáveis pelo aproveitamento dos espaços vazios urbanos, enfrentando o problema habitacional brasileiro da população de baixa renda e auxiliando na efetivação do direito constitucional à moradia (artigo $6^{\circ}$ CRFB) (BRASIL, 1988). Nesse sentido,

O PAR é um programa que apresenta uma forma diferente de acesso à moradia, por meio de uma operação financeira chamada "arrendamento mercantil", ou leasing. Através dessa forma de acesso, o imóvel que faz parte do patrimônio do Fundo de Arrendamento Residencial (FAR) - a fonte de recursos do programa, composta por um mix de recursos onerosos (FGTS) e não-onerosos (FAS, FINSOCIAL, FDS e PROTECH) - permanece sob a "propriedade fiduciária" da Caixa Econômica Federal (CAIXA), que é a gestora do fundo e representa o arrendador ativa e passivamente. Assim, a propriedade do imóvel é do FAR, enquanto o arrendatário paga uma taxa de arrendamento mensal, por um período de 15 anos, quando poderá obter o direito de optar pela aquisição do imóvel, mediante pagamento ou financiamento do saldo devedor, se houver. Em função dessa particularidade na titularidade do imóvel, para o mais eficiente funcionamento do sistema faz-se necessária a participação de uma administradora de imóveis para gerir os condomínios e os contratos de arrendamento do PAR (BONATES, 2008, p. 149).

Assim, o contratante do PAR efetua um contrato de leasing com a Caixa Econômica Federal e se imite na posse do imóvel, com o compromisso de pagar, mensalmente, a taxa de arrendamento e encargos inerentes ao bem, sob pena de perder a posse. Ao final do contrato, abre-se a possibilidade de aquisição da propriedade do bem.

A Lei $n$ ㅇ 10.188/2001 é o instrumento legislativo responsável por criar e regulamentar os principais aspectos do PAR e, em seu artigo 60, define que o arrendamento residencial é a operação efetuada no âmbito do PAR e que tem por objeto o arrendamento com opção de compra de bens imóveis. $O$ artigo $8^{\circ}$ traz detalhes sobre o contrato, destacando a cláusula impeditiva para venda ou cessão de direitos do imóvel em caso de aquisição de propriedade. Já o artigo 9o, objeto de análise das ações junto ao STF, prevê a possibilidade de reintegração de posse em caso de inadimplemento no pagamento das parcelas do arrendamento:

Art. $9^{\circ}$ : Na hipótese de inadimplemento no arrendamento, findo o prazo da notificação ou interpelação, sem pagamento dos encargos em atraso, fica configurado o esbulho possessório que autoriza o arrendador a propor a competente ação de reintegração de posse.

Em julgamento de agravo contra decisão de inadmissibilidade de recurso extraordinário, foi negada repercussão geral (conforme Supremo Tribunal Federal ARE 640.713, ministro relator Cezar Peluso, DJE, Brasília, 22/9/2011) e mantida decisão que concedeu a reintegração de posse à CEF em virtude de comprovada inadimplência e inércia da possuidora após ter sido devidamente notificada (BRASIL, 2017). O STF decidiu ainda pela constitucionalidade do artigo 9o da Lei no 10.188/2001, tendo o relator, ministro Luiz Fux, afirmado, em seu voto, que o objetivo da lei é de permitir o acesso à moradia por pessoas de baixa renda, sem descuidar do cumprimento das cláusulas contratuais. A justificativa apontada pelo ministro para o cumprimento da função social foi a de que

A determinação da reintegração da CEF na posse do imóvel objeto da demanda faz prevalecer a função social da posse, uma vez que outras pessoas de baixa renda, em condições de arcar com as obrigações contratuais, possuem interesse em ser beneficiadas pelo Programa em questão, além de a inadimplência do recorrente afetar o Fundo de Arrendamento Residencial - FAR (BRASIL, 2017). 
Embora o citado artigo $9^{\circ}$ da Lei $n 010.188 / 2001$ tenha sido o alvo do debate no STF, não se pode mais pensar em uma interpretação isolada dos dispositivos de uma lei. É preciso buscar a resposta para os casos concretos também nos dispositivos da Constituição, trabalhando o Direito de uma forma sistêmica. Nesse sentido, o Direito Civil constitucional impõe "uma hermenêutica com fins aplicativos, voltada à máxima realização dos valores constitucionais em vista das peculiaridades do caso concreto" (SCHREIBER; KONDER, 2016, p. 13).

O direito à moradia é reconhecido pela CRFB (BRASIL, 1988) como um direito social (art. $6^{\circ}$ ) e foi inserido no texto constitucional por meio da Emenda Constitucional ${ }^{\circ} 26$ de 2000. Para Fiuza e Santos (2015), o relevante caráter social que a posse apresenta é o de efetivar o direito à moradia, cumprindo, assim, sua função social.

O objetivo do PAR é fornecer o acesso à moradia a pessoas de baixa renda, atendendo, então, o programa proposto pela CRFB (BRASIL, 1988). O referido programa exige, como contraprestação, o cumprimento dos encargos financeiros para a manutenção da posse do imóvel. Em caso de inadimplemento, será, nos termos da lei, conferido um prazo para efetuar os pagamentos em atraso sob pena da perda o imóvel.

Conforme ressalta Fiuza (2014), o objetivo da função social da posse não é promover uma espécie de caridade cristã, de modo que o possuidor possa se manter na posse do imóvel sem arcar com suas responsabilidades. A função social estabelece um dever de cooperação entre os envolvidos, de modo a se ter uma utilização não individualista do bem.

A interpretação dada pelo ministro Luiz Fux, contudo, embora tenha identificado a função social da posse com o direito fundamental à moradia, mostra-se, no mínimo, questionável, uma vez que despreza as particularidades do caso concreto, desamparando todos aqueles que, por qualquer razão e em qualquer situação, não conseguiram honrar seus compromissos. Ou seja, a decisão do ministro desfavorece aqueles que mais necessitam, muitas vezes protegendo somente o investimento do banco estatal.

Caso o não pagamento ocorreu no início do contrato, a reintegração de posse poderia ser a medida mais correta, desde que também oportunizasse àqueles que não possuíam condições financeiras de arcar com os custos de sua moradia, a efetivação do seu direito a esta. Uma solução seria a imediata inscrição destes nos programas governamentais de acesso à moradia.

Já naquelas situações em que houve pagamento vultuoso das prestações, uma possível solução para a compatibilização da função social da posse dos imóveis que fazem parte do PAR, e consequentemente do direito fundamental à moradia, é a aplicação da teoria do adimplemento substancial. Tal teoria parte de uma nova concepção de adimplemento, a qual pode ser definida como a satisfação dos interesses legítimos do credor, mesmo quando a obrigação não foi inteiramente cumprida. Desse modo, a teoria do adimplemento substancial seria aplicada em situações nas quais há pouca discrepância entre as prestações efetivamente adimplidas e o restante das prestações devidas (TERRA; GUEDES, 2017), posto que o montante pago já teria sido o suficiente para pagar o investimento do credor e ainda the proporcionar algum lucro. Assim, em vez de permitir que o credor se apropriasse do imóvel, o que lhe daria um lucro ainda maior no caso de nova venda, ele poderia apenas cobrar o restante da dívida pelas vias ordinárias. No Direito brasileiro, apesar de inexistir previsão legal expressa, a teoria do adimplemento substancial encontra fundamento no princípio da boa-fé objetiva, mais especificamente em sua função de vedar o exercício abusivo de posição jurídica, conforme aponta Anderson Schreiber (2007).

O Superior Tribunal de Justiça (STJ) estabeleceu, no REsp. 76.362/MT (BRASIL, 1995), os critérios para aplicação da teoria do inadimplemento substancial no Direito brasileiro. O primeiro requisito é a existência de legítimas expectativas para o cumprimento da obrigação geradas pelo comportamento das partes. O segundo consiste no fato de que o valor restante a ser pago deveria ser ínfimo quando considerado o total do negócio. Por fim, o terceiro requisito analisou a possibilidade de conservação da eficácia do negócio jurídico, sem prejudicar o credor de pleitear a quantia devida por outros meios. Com isso, o Superior Tribunal de Justiça firmou a concepção da necessidade de buscar as peculiaridades do caso concreto a fim de fornecer a sua solução. Dessa forma, a teoria do adimplemento substancial fornece critérios objetivos para compatibilizar os interesses do credor e do devedor, evitando a resolução do contrato.

Ademais, ressalta-se que a teoria do adimplemento substancial não rompe com a boa-fé contratual. 0 Direito obrigacional brasileiro adota o modelo de separação relativa em relação à manifestação de vontade (VIEIRA; OLIVEIRA, 2016), ou seja, quando o sujeito manifesta sua vontade de se obrigar ao negócio jurídico, 
está manifestando também sua vontade em o adimplir. Desse modo, quando nasce a relação obrigacional, os sujeitos estão cientes dos seus deveres um para com o outro. A teoria do adimplemento substancial busca a aplicação do princípio da preservação dos contratos, desde que as partes estejam agindo de boa-fé, sem se beneficiarem da própria torpeza.

Apesar da teoria do adimplemento substancial não ter sido aplicada pelo STF no caso analisado, poderia ter sido uma solução para demais casos em que faltou uma parcela mínima do valor acordado. A mera aplicação da letra fria da lei pode levar ao comprometimento da boa-fé objetiva, uma vez que o rompimento do contrato é medida gravosa, devendo este, portanto, ser preservado sempre que possível.

\section{CONCLUSÃO}

A CRFB/1988 trouxe impactos significativos no Direito Civil brasileiro por alguns motivos. O primeiro por tratar, em seu texto, de assuntos tradicionais do Direito Privado; o segundo por alterar a relação entre Direito Público e Direito Privado e, em terceiro, por impor o dever do Direito Privado de efetivar o programa constitucional e atender aos objetivos e fundamentos da República brasileira. Esses impactos receberam o nome de constitucionalização do Direito Civil.

A constitucionalização do Direito Civil forçou uma releitura dos institutos tradicionais desse ramo do direito. A posse deixou de ser definida apenas a partir do corpus e do animus, os conceitos tradicionais de Savigny e Jhering, para incluir o cumprimento da função social em sua definição. Com isso, para se definir a posse, não basta a presença do corpus e do animus, exige-se também a presença da função social, ou seja, cumprir uma destinação extrínseca a ser atendida pelo possuidor, exigindo o cumprimento de obrigações positivas para promover interesses sociais como a moradia ou o trabalho. Assim, a posse atende à função social quando sua aplicação efetiva o programa constitucional.

Em relação à aplicação do conceito de função social da posse em um caso concreto, analisou-se o acórdão ARE 1047694 do STF. Com isso constatou-se que a aludida decisão se mostra questionável, uma vez que não se atentou para as peculiaridades do caso concreto, demonstrando uma preferência pela aplicação da letra fria da lei. Assim, apesar de o ministro Luiz Fux ter identificado a função social da posse com o direito fundamental à moradia, a desrespeitou ao determinar a reintegração do imóvel em qualquer hipótese de inadimplemento contratual.

Ainda ressalta-se que, apesar da função social da posse não poder servir como fundamento para a violação das obrigações pactuadas, deve-se efetuar uma análise das peculiaridades de cada caso concreto a fim de se apurar em que etapa se deu o inadimplemento das obrigações pactuadas. Caso o inadimplemento tenha ocorrido no início do contrato, a reintegração do imóvel mostra-se uma medida viável. Por outro lado, caso o montante devido possua um valor ínfimo. Deve-se providenciar o pagamento da dívida de forma razoável e assim evitar a reintegração de posse. Tal medida permitiria uma compatibilização entre o Direito obrigacional e a função social da posse.

\section{REFERÊNCIAS}

AMARAL, Francisco. A descodificação do direito civil brasileiro. Revista da Academia Brasileira de Letras Jurídicas, Rio de Janeiro, n. 13-14, p. 109-125, 1으 e 20 sem. 1998.

BONATES, Mariana Fialho. O Programa de Arrendamento Residencial - PAR: acesso diferenciado à moradia e à cidade. Risco: Revista de Pesquisa em Arquitetura e Urbanismo, $\mathrm{n}^{\circ}$ 7, 2008. Disponível em: http://www.iau.usp.br/revista_risco/Risco7-pdf/02_art10_risco7.pdf. Acesso em: 21 jan. 2018.

BRASIL. 1995. STJ - REsp 76362 MT 1995/0050635-1. Relator: min. RUY ROSADO DE AGUIAR, Diário de Justiça Eletrônico. Data de Julgamento: 11/12/1995, Data de Publicação: DJ 1ㅇ/4/1996.

BRASIL. 2011. STF - ARE: 640.713. Relator: min. Cezar Peluso, Diário de Justiça Eletrônico, Data de Publicação: DJe 22/9/2011. BRASIL. 2017. STF - ARE: 1047694/RJ. Relator: min. Luiz Fux, Diário de Justiça Eletrônico, Data de Julgamento: 30/5/2017, Data de Publicação: DJe-116 2/6/2017.

BRASIL. Código Civil de 1916. Lei no 3.071, de 1o de janeiro de 1916. Diário Oficial da União. Brasília, DF: Senado Federal, 1916. BRASIL. Código Civil de 2002. Lei no 10.406, de 10 de janeiro de 2002. Diário Oficial da União. Brasília, DF: Senado Federal, 2002. 
BRASIL. Constituição da República dos Estados Unidos do Brasil. Diário Oficial da União. Rio de Janeiro, RJ: Senado Federal, 1934.

BRASIL. Constituição da República Federativa do Brasil. Diário Oficial da União. Brasília, DF: Senado Federal, 1988.

BRASIL. Lei n 8245 de 18 de outubro de 1991. Diário Oficial da União. Brasília, DF: Senado Federal, 1991.

BRASIL. Lei no 10.188 de 12 de fevereiro de 2001. Diário Oficial da União. Brasília, DF: Senado Federal, 2001 a.

BRASIL. Lei no 10.257 de 10 de julho de 2001. Diário Oficial da União. Brasília, DF: Senado Federal, 2001 b.

CASTRO, Áurea Lúcia Chaves. A função social da posse: breve estudo sobre a função social da posse e consequências em razão do seu nocivo e do abuso de direito. In: SOUZA, Adriano Stanley Rocha (coord.). Estudos avançados da posse e dos direitos reais. Belo Horizonte: Del Rey, 2010.

CEF. Caixa Econômica Federal. PAR - Programa de arrendamento residencial. 2017. Disponível em: http://www1.caixa.gov.br/ gov/gov_social/municipal/programa_des_urbano/programas_habitacao/par/index.asp. Acesso em: 28 nov. 2017.

DONIZETTI, Elpídio; QUINTELLA, Felipe. Curso didático de Direito Civil. São Paulo: Atlas, 2014.

FARIAS, Cristiano Chaves de; ROSENVALD, Nelson. Curso de Direito Civil - Direitos Reais, vol. 5, 10. ed. rev., ampl. e atual. Salvador: JusPodivm, 2014.

FIUZA, César Augusto de Castro; SANTOS, Clarice Fernandes. A função social da posse no ordenamento jurídico brasileiro. In: CONGRESSO NACIONAL DO CONPEDI, 24., Direito civil contemporâneo I. Coordenadores Christian Sahb Batista Lopes, José Sebastião de Oliveira, Maria Goretti Dal Bosco, 2015, Belo Horizonte, MG. Anais [...]. Florianópolis: Conpedi, 2015.

FIUZA, César. Crise e interpretação no Direito Civil da escola da exegese às teorias da argumentação. In: FIUZA, César; NAVES, Bruno Torquato de Oliveira; SÁ, Maria de Fátima de (coord.). Direito civil: atualidades. Belo Horizonte: Del Rey, 2003.

FIUZA, César. Direito civil: curso completo. 10. ed. rev., atual. e ampl. Belo Horizonte: Del Rey, 2007.

FIUZA, César. Direito civil: curso completo. 17. ed. rev., atual. e ampl. Belo Horizonte: Del Rey, 2014.

MIRANDA FILHO, Juventino Gomes de. A função social da posse. In: SOUZA, Adriano Stanley Rocha (coord.). Estudos avançados da posse e dos direitos reais. Belo Horizonte: Del Rey, 2010. p. 1-59.

MORAES, Maria Celina Bodin de. A caminho de um direito civil constitucional. Revista Estado, Direito e Sociedade, PUC-Rio, vol. I, 1991.

MOTA PINTO, Carlos Alberto da et. al. Teoria geral do direito civil. 4. ed. Coimbra: Editora Coimbra, 2012.

PERLINGIERI, Pietro. O direito civil na legalidade constitucional. Rio de Janeiro: Renovar, 2008.

PERLINGIERI, Pietro. Perfis de direito civil. Tradução Maria Cristina de Cicco. 3. ed. rev. e ampl. Rio de Janeiro: Renovar, 2002.

ROSA, Marizélia Peglow da. A função social da posse, no direito brasileiro atual, enquanto instrumento de efetivação dos direitos fundamentais ao trabalho e à moradia. In: ENCONTRO PREPARATÓRIO PARA O CONGRESSO NACIONAL DO CONPEDI - CONSELHO NACIONAL DE PESQUISA E PÓS-GRADUAÇÃO EM DIREITO, 16., 2007, Campos dos Goytacazes. Anais [...]. Florianópolis: Conpedi, 2007. p. 2.236-2.254.

SCHREIBER. Anderson. A tríplice transformação do adimplemento. Revista Trimestral de Direito Civil: RTDC, v. 8, n. 32, p. 3-27, out./dez. 2007.

SCHREIBER, Anderson; KONDER, Carlos Nelson. Uma agenda para o direito civil-constitucional. Revista Brasileira de Direito Civil, vol. 10, out./dez. 2016. Disponível em: https://www.ibdcivil.org.br/image/data/revista/volume10/rbdcivil_vol_10_00_ completo.pdf. Acesso em: 21 jan. 2018.

SILVA, Marcos Claro da; SETTI, Bruna Migliaccio. A eficácia social da posse. In: ENCONTRO NACIONAL DO CONPEDI, 26., Direito civil Constitucional. Coordenadores João Costa Ribeiro Neto e Regina Vera Villas Boas 2017, Brasília-DF. Anais [...]. Florianópolis: Conpedi, 2017.

SOUZA, Leonardo Antônio Galvani de. Teoria pós-moderna da posse. 2014, 171f. Tese (Doutorado em Direito) - Pontifícia Universidade Católica de Minas Gerais, Belo Horizonte, 2014.

STANLEY, Adriano. Direito das coisas. 4. ed. Belo Horizonte: Del Rey, 2015.

TEPEDINO, Gustavo. A constitucionalização do direito civil: perspectivas interpretativas diante do novo Código. In: FIUZA, César; NAVES, Bruno Torquato de Oliveira; SÁ, Maria de Fátima de (coord.). Direito civil: atualidades. Belo Horizonte: Del Rey, 2003. p. 115-130.

TEPEDINO, Gustavo. Normas constitucionais e direito civil na construção unitária do ordenamento. Revista de Direito do Estado: $R D E$, Instituto de Direito do Estado e Ações Sociais, n. 7, jul./set. 2007.

TEPEDINO, Gustavo. Temas de direito civil. 3. ed. Rio de Janeiro: Renovar, 2004.

TERRA, Aline de Miranda Valverde; GUEDES, Gisela Sampaio da Cruz. Adimplemento substancial e tutela do interesse do credor: análise da decisão proferida no RESP 1.581.505. Revista Brasileira de Direito Civil - RBDCivil, Belo Horizonte, vol. 11, jan./ mar. 2017. 
VIEIRA, Marcelo de Mello. A posse e sua interpretação no atual direito civil brasileiro. In: POLI, Leonardo Macedo; SÃO JOSÉ, Fernanda (org.). Direito civil na contemporaneidade 2. Belo Horizonte: D’Plácido Editora, 2015.

VIEIRA, Marcelo de Mello; OLIVEIRA, Lucas Costa de. Boa-fé, deveres anexos e violação positiva do contrato: observações sobre o processo obrigacional. In: QUEIROZ, Mônica et. al. (org.). Direito Civil em debate - reflexões críticas sobre temas atuais. Belo Horizonte: D’Plácido Editora, 2016. 